\title{
MicroRNAs in bovine milk exosomes are bioavailable in humans but do not elicit a robust pro-inflammatory cytokine response
}

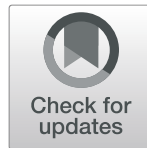

\author{
Ezra Mutai ${ }^{1}$, Amanda E. Ramer-Tait ${ }^{2}$ and Janos Zempleni ${ }^{*^{*}}$ (B)
}

\begin{abstract}
Background: Bovine milk exosomes are studied for their roles as bioactive food compounds and as vehicles for drug delivery. Both lines of investigation converge on immune function, e.g., immune regulation by absorption of microRNAs encapsulated in milk exosomes across species boundaries, and the possibility of exosomes and their cargos triggering an immune response if used in drug delivery. This study assessed the bioavailability of immune-related microRNAs from bovine milk and changes in plasma cytokine concentrations after milk consumption in humans, and the secretion of cytokines by human peripheral blood mononuclear cells (PBMCs) cultured with milk exosomes transfected with immune-relevant microRNAs.

Results: Human plasma samples were collected before and at timed intervals after a milk meal and analyzed for concentrations of six immune-relevant microRNAs and nine cytokines. The peak plasma concentrations of miR-15b-5p, miR21-5p, miR-106b-5p, and miR-223-3p were $60 \pm 9.80 \%$ to $162 \pm 31.80 \%$ higher after milk consumption ( $C_{\mathrm{t}}$ values $23 \pm 1.2$ to $26 \pm 1.1$ cycles) compared to baseline values $(P<0.05)$. Plasma concentrations of TNF-alpha were not significantly different before versus after milk consumption; eight other cytokines were below detection limit. PBMCs were collected before and six hours after milk consumption and cultured with or without concanavalin A (ConA). TNF-alpha, IL-1B, IL-6 and IL-10 were detectable in culture media, but concentrations did not depend on milk consumption prior to PBMC isolation $(P>0.05)$. When PBMC cultures from fasted subjects were supplemented with milk exosomes that had been transfected with immune-relevant microRNAs, the concentrations of IL-1 1 , IL-6, IL-10 and TNF-alpha were $29 \pm 12 \%$ to $220 \pm 33 \%$ higher than controls cultured with non-transfected exosomes $(P<0.05)$, but cytokine concentrations were not different compared with control exosomes transfected with scrambled microRNA $(P>0.05)$.
\end{abstract}

Conclusions: MicroRNAs in bovine milk exosomes are bioavailable. Milk exosomes do not elicit an increase of plasma cytokines following oral administration.

Trial registration: ISRCTN registry ID: 16329971. Retrospectively registered on February 7th, 2019.

Keywords: Bioavailability, Bovine, Cytokines, Human, microRNA, Milk, Peripheral blood mononuclear cells

\section{Background}

Exosomes are nano-sized particles that play essential roles in cell-to-cell communication [1]. Communication is achieved through the transfer of diverse cargos such as various species of RNAs, proteins, and lipids from donor to recipient cells [1-3]. Among exosome cargos, microRNAs (miRs) are of particular interest, because they hybridize

\footnotetext{
*Correspondence: jzempleni2@unl.edu

${ }^{1}$ Departments of Nutrition and Health Sciences, University of

Nebraska-Lincoln, 316C Leverton Hall, Lincoln, NE 68583, USA

Full list of author information is available at the end of the article
}

with complementary sequences in $3^{\prime}$-untranslated regions in mRNA and silence genes through triggering mRNA degradation or preventing translation of mRNA $[4,5]$. More than $60 \%$ of human (Homo sapiens, hsa) mRNAs contain putative bindings sites for the approximately $2000 \mathrm{miRs}$ encoded in the human genome [6,7]. MiRs regulate virtually every gene network in humans and are implicated in numerous physiological and pathological conditions in humans $[8,9]$. The negative regulation of genes by miRs is of particular importance for fine tuning regulatory circuitries in the immune response [10].

(C) The Author(s). 2020 Open Access This article is distributed under the terms of the Creative Commons Attribution 4.0 International License (http://creativecommons.org/licenses/by/4.0/), which permits unrestricted use, distribution, and reproduction in any medium, provided you give appropriate credit to the original author(s) and the source, provide a link to the Creative Commons license, and indicate if changes were made. The Creative Commons Public Domain Dedication waiver (http://creativecommons.org/publicdomain/zero/1.0/) applies to the data made available in this article, unless otherwise stated. 
Traditionally, miRs have been considered endogenous regulators of genes, consistent with observations that miRs are encoded by endogenous genes and loss of miR maturation in Dicer knockout mice is embryonic lethal [11-16]. The paradigm that miRs are exclusively obtained from endogenous synthesis has been challenged in reports suggesting that dietary miRs in plants and bovine (Bos taurus, bta) milk are bioavailable and contribute to the body pool of miRs in humans and animals $[17,18]$. For example, in 2012 evidence emerged that MIR-168a from rice (Oryza sativa; osa-MIR-168a) is detectable in human and animal sera, and osa-MIR-168a decreases the expression of LDL receptor adapter protein $1 \mathrm{mRNA}$, thereby inhibiting LDL receptor expression in mouse liver [17]. Encapsulation of miRs in exosomes confers resistance to the harsh conditions in dairy processing plants and the human gastrointestinal tract and subsequently facilitates the intestinal absorption of miRs [19-22]. Discoveries regarding the bioavailability of milk miRs were confirmed by five independent laboratories (reviewed in [23]). That review also discusses the limitations of studies that failed to demonstrate bioavailability of milk miRs.

Studies of miRs and their exosome shells in bovine milk have gained considerable traction in two lines of investigation, namely the roles of miRs and exosomes as bioactive food compounds and the use of milk exosomes as vehicles for drug delivery. For example, evidence suggests that dietary depletion of milk exosomes and RNA elicits phenotypes such as a 40-fold increase of purine metabolites in human and murine body fluids and tissues and a moderate loss of grip strength in mice $[24,25]$. Milk exosomes have been used to deliver drugs to tumor sites in mice [26, 27]. Both lines of investigation converge in immune function, e.g., immune regulation by miRs across species boundaries and the possibility of adverse effects caused by administration of immunogenic exosomes in drug delivery.

Bovine milk exosomes contain miRs that have been implicated in immune function, e.g., miR-15b-5p, miR-21-5p, miR-34a-5p, miR-106b-5p, miR-155-5p, and miR-223-3p $[7,10,28]$. These miRs have nucleotide sequences identical to the human orthologs and therefore will bind to complementary sequences in human mRNA [29]. This study assessed the bioavailability of immune-related microRNAs from bovine milk and immune responses to milk feeding in humans as well as the secretion of cytokines by human peripheral blood mononuclear cells (PBMCs) cultured with miR-transfected milk exosomes.

\section{Results}

MiRs analyses in bovine milk and bovine milk exosomes The amounts of the six miRs quantified using RT-qPCR analyses were similar in bovine milk and bovine milk exosomes. When using < 30 PCR cycles as detection limit (Ct, detection limit), miR-15b, miR-21, miR-106b and miR-223 were easily detectable in both milk and exosomes, whereas miR-34a and miR-155 were borderline detectable (Fig. 1).

\section{Plasma levels of immune-related miRs}

We assessed plasma levels of six immune-related miRs before and at timed intervals after consumption of $1 \mathrm{~L}$ milk by using reverse transcriptase quantitative PCR (RT-qPCR) in 12 healthy subjects; miR-1-3p was used as negative control because it is not detectable in bovine milk. A synthetic miR, miSPIKE (IDT DNA, Inc.) was added to plasma samples after denaturation with lysis buffer and served as external standard. MiSPIKE was used to normalize for miR extraction efficiency and any losses occurring during extraction [18]. Four miRs were detectable in human plasma when the detection limit was defined as $\mathrm{Ct}=30$ PCR cycles: $\mathrm{miR}-15 \mathrm{~b}-5 \mathrm{p}$, miR-215p, miR-106b-5p and miR-223-3p (Table 1); miR-34a-5p and miR-155-5p were not detectable before and after milk consumption. The Ct values for miR-1-3p and miSpike were not significantly different among time points. Pharmacokinetics analysis of plasma concentration versus time curves (AUC) suggest that plasma levels vary greatly among miRs, plasma levels peaked between three and six hours, and the apparent bioavailability varied among miRs (miR-223-3p > miR-21-5p > miR-15b-5p > miR-106b-5p; Table 2). For example, the percent increase of postprandial peak plasma concentration was $60 \pm 9.80 \%$ and $162 \pm 31.80 \%$ for miR-106b-5p and miR-

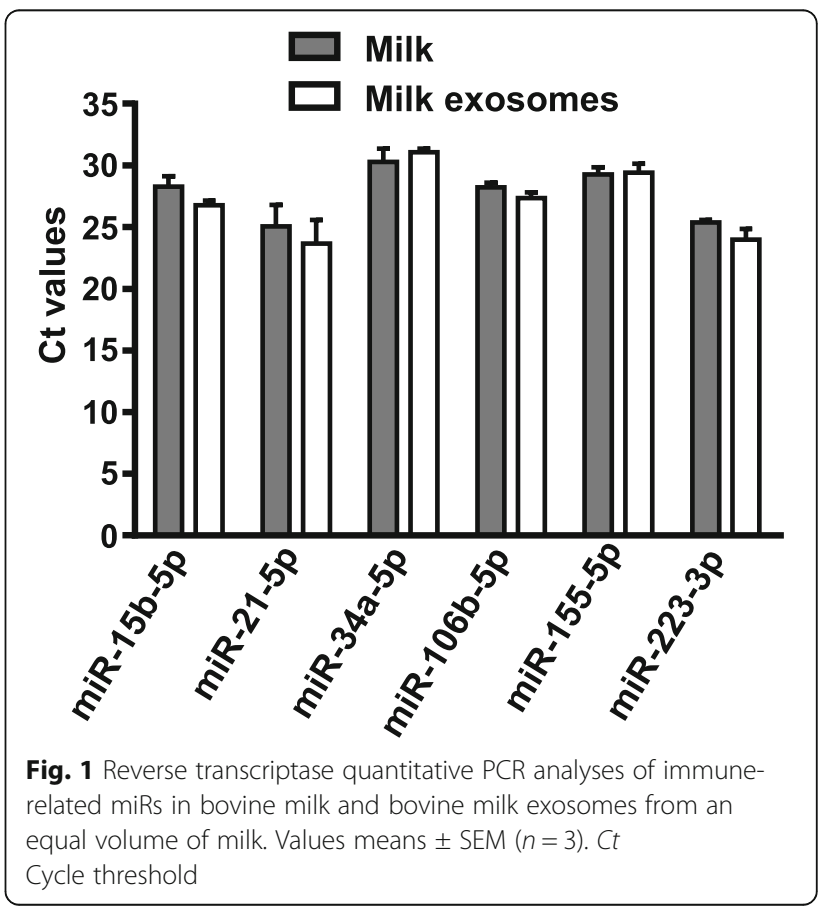


Table $1 C_{t}$ values of plasma miRs before and after milk consumption in healthy adults

\begin{tabular}{|c|c|c|c|c|c|c|c|c|}
\hline \multicolumn{9}{|c|}{$C_{t}$ values } \\
\hline Hours & miSPIKE control & miR-15b-5p & miR-21-5p & miR-106b-5p & miR-223-3p & miR-34a-5p & miR-155-5p & miR-1-3p \\
\hline 0 & $19 \pm 2.1$ & $28 \pm 2.4$ & $25 \pm 2.3$ & $28 \pm 2.2$ & $25 \pm 2.8$ & $33 \pm 2.3$ & $33 \pm 1.9$ & $34 \pm 1.5$ \\
\hline 3 & $18 \pm 2.0$ & $26 \pm 2.3$ & $24 \pm 1.5$ & $26 \pm 1.8$ & $25 \pm 1.7$ & $35 \pm 2.2$ & $32 \pm 2.3$ & $34 \pm 0.9$ \\
\hline 6 & $18 \pm 1.1$ & $25 \pm 1.6^{a}$ & $23 \pm 1.2^{\mathrm{a}}$ & $26 \pm 1.1^{a}$ & $24 \pm 0.6^{a}$ & $35 \pm 1.6$ & $33 \pm 2.4$ & $33 \pm 1.9$ \\
\hline 9 & $19 \pm 1.9$ & $27 \pm 2.8$ & $24 \pm 1.9$ & $27 \pm 2.4$ & $25 \pm 1.8$ & $35 \pm 1.8$ & $33 \pm 2.9$ & $33 \pm 1.5$ \\
\hline
\end{tabular}

${ }^{1}$ Values are means $\pm S D, n=12,{ }^{a} P<0.05$ vs. hour 0 . Ct cycle threshold, miR microRNA

223-3p, respectively. Taken together, the results indicate that some, but not all, miRs in bovine milk exosomes are bioavailable in humans after milk consumption.

A previous report suggested that miR analysis may be confounded by contamination of NucleoSpin miR plasma columns with microbial RNAs, but we could not reproduce these findings [30]. We tested for column contamination by passing molecular biology grade water through hypochlorite-treated and non-treated columns and compared the $\mathrm{Ct}$ values of the six miRs in the two treatments by RT-qPCR ( $n=5$ per treatment). Ct values were greater than 35 in all samples tested. Absence of contamination notwithstanding, we erred on the side of caution and treated columns with $0.5 \%$ sodium hypochlorite prior to miR extraction from plasma [30].

\section{Concentrations of cytokines in plasma}

Consumption of milk had no effect on cytokine concentrations in human plasma. Nine cytokines were included in the customized multiplex assay, based on the rationale that distinct lineages of the immune cells secrete different cytokines. Out of the nine cytokines tested, only TNF-alpha was detectable in plasma collected before and after milk consumption; the apparent increase of plasma TNF-alpha concentrations three hours after milk consumption compared with baseline was not statistically significant ( $p=0.08$ for one-way ANOVA; Fig. 2). These results suggest that consumption of milk does not elicit an increase in cytokine concentrations in human plasma.

\section{Concentrations of cytokines in PBMC culture media}

Milk consumption alone did not prime PBMCs to increase the net secretion of IL-1 $\beta$, IL- 6 , IL-10 and TNF-alpha compared with PBMCs collected before milk consumption ex vitro. However, PBMCs from participants consuming milk did produce significantly higher levels of these cytokines following stimulation with concanavalin A (ConA) for $24 \mathrm{~h}$ (Fig. 3). ConA treatment alone did not elicit changes of cytokine concentrations in culture media. For media collected at $48 \mathrm{~h}$ and $72 \mathrm{~h}$, patterns of cytokine concentrations were the same as for the first $24 \mathrm{~h}$ of culture (Additional files 1 and 2). The concentrations of IL-2, IL-4, IL-5, IL-17A and interferon gamma (IFN- $\gamma$ ) at 24, 48 and $72 \mathrm{~h}$ from cultures of PBMCs isolated before and six hours after a milk meal were not affected by milk consumption or ConA (Table 3).

Cytokine concentrations in culture media were not altered if PBMCs from fasted subjects were cultured with exosomes transfected with equimolar concentrations of a mixture of four immune-relevant miR or a scrambled miR control compared to concentrations in media from PBMCs incubated with non-transfected exosomes (Fig. 4). For example, the concentrations of TNF-alpha were not significantly different in media supplemented with $10^{10}$ $/ \mathrm{ml}$ milk exosomes compared to media supplemented with $10 \% / \mathrm{ml}$ exosomes. Likewise, co-stimulation with ConA and transfection of exosomes with immunerelevant miRs or scrambled miRs had no significant effect on TNF-alpha concentrations in media. The apparent absence of effect was likely due to the large variation in TNF-alpha concentrations among samples. We conducted

Table 2 Pharmacokinetics analysis of plasma miR time curves after milk meal in healthy adults ${ }^{\mathrm{a}}$

\begin{tabular}{|c|c|c|c|c|c|}
\hline Variable & miR-15b-5p & miR-21-5p & miR-106b-5p & miR-223-3p & miR-1-3p \\
\hline Baseline $^{\mathrm{b}}, \mathrm{fmol} / \mathrm{L}$ & $682 \pm 150$ & $2048 \pm 190$ & $400 \pm 110$ & $822 \pm 120$ & $94 \pm 9.8$ \\
\hline$C_{\max } f \operatorname{mol} / / \mathrm{L}$ & $1289 \pm 360$ & $5048 \pm 940^{b}$ & $641 \pm 140$ & $2152 \pm 570^{a}$ & $99 \pm 4.9$ \\
\hline$\%$ increase $^{c}$ & $89 \pm 11.80$ & $147 \pm 23.20$ & $60 \pm 9.80$ & $162 \pm 31.80$ & - \\
\hline$t_{\max }, h$ & $3.7 \pm 0.3$ & $3.2 \pm 0.6$ & $4.1 \pm 0.5$ & $3.8 \pm 0.7$ & - \\
\hline$A \cup C^{d},(f m o l / L) \times h$ & $3018 \pm 120^{c}$ & $12,669 \pm 760^{c}$ & $1531 \pm 48^{c}$ & $5377 \pm 320^{c}$ & - \\
\hline
\end{tabular}

${ }^{a}$ Values are means $\pm \mathrm{SEM}, n=12 .{ }^{a} P<0.05,{ }^{\mathrm{b}} P<0.01,{ }^{c} P<0.0001$, vs. baseline. AUC Area under the plasma concentration versus time curve, $C_{\max }$ Maximal plasma concentration, miR MicroRNA, $t_{\max }$ Time of peak concentration

${ }^{\mathrm{b}}$ Plasma concentration at time $0 \mathrm{~h}$

${ }^{\mathrm{C}} \mathrm{C}_{\max }$ vs. baseline

${ }^{\mathrm{d}}$ For hours 0-9 


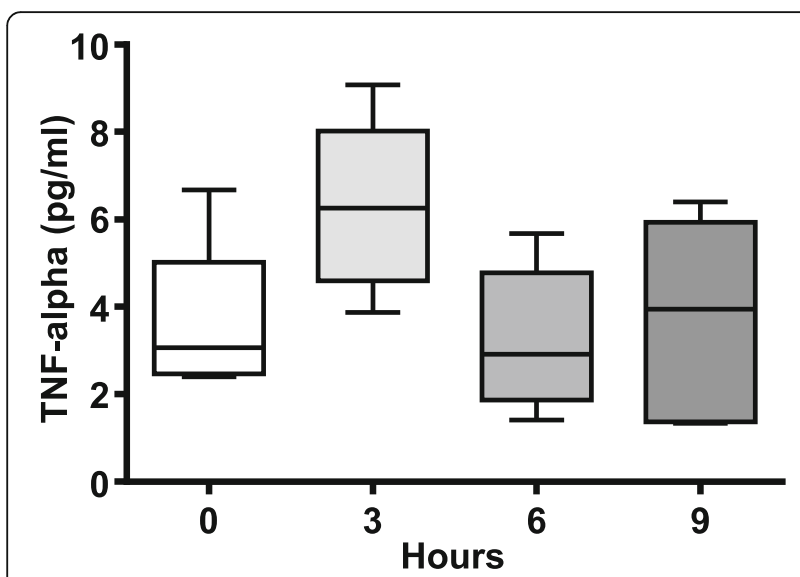

Fig. 2 Box plots of TNF-alpha plasma concentration before and at timed intervals after a milk meal. Boxes represents the 5th and 95th percentiles, horizontal bars are the medians, and error bars indicate minimum and maximum values. $p=0.08$ versus hour 0 (one-way ANOVA and Sidak's multiple comparisons posthoc test; $n=5$ ). TNFalpha Tumor necrosis factor-alpha

a power calculation $(\alpha=0.05, \beta=0.8)$ using the mean \pm SD of TNF-alpha concentrations $(53.2 \pm 49.8 \mathrm{pg} / \mathrm{ml})$ in media from PBMCs incubated with $10^{10} / \mathrm{ml}$ naïve milk exosomes without ConA. The test hypothesis was that incubation of PBMC cultures with exosomes loaded with immune-related miRs does not affect the net secretion of cytokines. Fifty-nine samples would be needed to detect a $30 \%$ change of TNF-alpha concentrations. Patterns of media concentrations of IL-1 $\beta$, IL- 6 and IL- 10 were variations of that described for TNF-alpha, including patterns of data variation. Taken together, our data suggest that bovine milk exosomes elicit cytokine secretion by PBMCs only if co-stimulated with ConA ex vivo in humans.

\section{Discussion}

This study represents an important advance in the field of milk exosomes and their RNA cargos with respect to two lines of investigation, bioactive food compounds in human nutrition and drug delivery by milk exosomes. Our results are notable because they suggest that some, but not all, miRs in milk exosomes enter the plasma space after milk consumption. A previous study suggests that postprandial increases in miR plasma levels are due to absorption of miRs from milk as opposed to milk consumption stimulating endogenous synthesis [31]. Beyond this idea, it has also been shown that dietinduced stimulation of endogenous miR synthesis also contributes to postprandial increases of plasma miRs [32]. Our RT-qPCR analyses demonstrated the presence of the six immune-related miRs in bovine milk and bovine milk exosomes. Our analyses are consistent with previous studies, which also detected the six miRs in bovine milk [19, 28]. Our observed absence of a postprandial increase for miR-34a-5p and miR-155-5p in plasma should not be confused with an absence of absorption, but may instead result from a first-passage elimination in the intestinal mucosa or liver as proposed previously for miR-375 [31, 33]. In addition, the concentrations of miR-34a are low in bovine milk exosomes; theoretically, quantitatively minor increases in plasma miR-34a concentrations might have escaped detection [19]. The limitations of previous studies that failed to detect absorption of miRs from milk are discussed in a recent review and were attributed to a lack of miR encapsulation in exosomes, compromised sample integrity, first-passage elimination and biased bioinformatics analysis [23]. It appears reasonable to conclude that both absorption of miRs from milk and milk-induced endogenous synthesis of miRs occur.

Our discoveries regarding the immunogenic potential of milk miRs are important in the context of both milk exosomes and miR cargos as bioactive food compounds and exosomes for drug delivery. Previous studies have revealed pathways by which select miRs elicit immune responses by binding to toll-like receptors (TLRs) or via surface antigen-mediated delivery of exosomes to immune cells [34-36]. The binding of single-stranded RNA to TLR3, TLR7 and TLR8 as well as the binding of double-stranded RNA to TLR3 are hallmarks of an antiviral response [37-39]. RNA binding to TLRs may trigger two distinct antiviral responses, i.e., NF- $\mathrm{kB}$ dependent expression of antiviral cytokines such as IL$1 \beta$ and TNF-alpha and interferon regulatory factor- 3 (IRF-3)-dependent expression of Type I interferons, including interferon beta (IFN- $\beta$ ) [40, 41]. Foreign exosomes are known to accumulate in resident liver and spleen macrophages and that human macrophages transport milk exosomes and their miR and mRNA cargos [42-44]. In the light of these previous studies, one may not expect our observed absence of a net increase in plasma cytokine concentrations following milk consumption in humans and in PBMC cultures supplemented with naïve milk exosomes. Caution needs to be exercised when interpreting these apparently contradictory results. Our study examined the net (apparent) secretion of cytokines into plasma and media without considering the opposing effects of secretion and elimination. There is precedent for suggesting that an increase of cytokine endocytosis may override an increase in secretion. In a previous study, the essential nutrient biotin caused an apparent decrease in the secretion of IL- 2 by PBMCs ex vivo, but the observed decrease was caused by a biotin-dependent increase in IL-2 endocytosis by PBMCs due to increased expression of IL-2 receptor- $\gamma$ $[45,46]$. Future studies that perform a comprehensive analysis of miR-dependent pathways of cytokine secretion and endocytosis are warranted. 


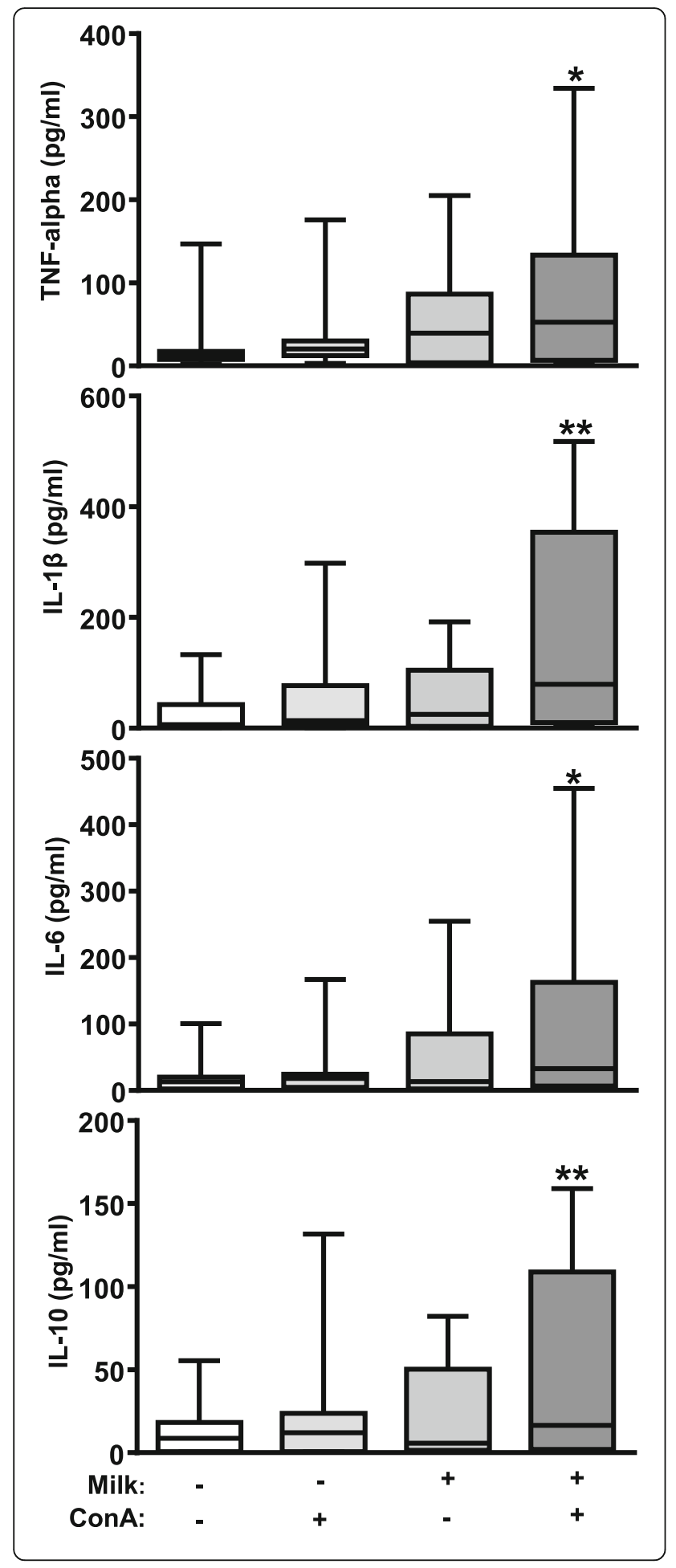

In drug delivery, the objective is to leverage exosome stability and bioavailability for delivering siRNA and other drugs to cancer sites [27, 47]. Ideally, delivery is achieved without triggering an immune response while allowing RNA-based drugs to elicit a biological response in the recipient organism.
Fig. 3 Secretion of TNF-alpha, IL-1 $\beta$, IL-6, and IL-10 by human PBMC cultures ex vivo. PBMCs were isolated before and six hours after milk consumption and cultured with or without ConA for $24 \mathrm{~h}$. Boxes represents the 5th and 95th percentiles, horizontal bars are the medians, and error bars indicate the maximum values. ${ }^{*} p<0.05$, ${ }^{* *} p<0.01$ versus milk-free and ConA-free controls. (Friedman rank sum test followed by pairwise comparisons using Nemenyi multiple comparison test; $n=12$ ). ConA Concanavalin A, IL Interleukin, PBMC Peripheral blood mononuclear cell, TNF-alpha Tumor necrosis factor-alpha

Our study suggests that milk exosomes meet these criteria. First, supplementation of PBMC cultures with naïve milk exosomes did not elicit an increase in the apparent secretion of cytokines into culture media. This observation is consistent with previous studies suggesting absence of immune responses and inflammation in mice treated with oral milk exosomes [26]. While we and others did not assess immune reactions after intravenous exosome administration in this study, we have not observed frank adverse reaction to intravenous milk exosome injections in mice in a previous study [31]. Second, upon loading with pharmacological doses of $\mathrm{miR}$, the cargo was able to elicit a biological response in the form of increased cytokine secretion by PBMCs ex vivo. The secretion of cytokines was not specific for pro-inflammatory cytokines but instead presented as a general upregulation of PBMC activity that also included increased production of the antiinflammatory cytokine IL-10 [48]. A major obstacle

Table 3 Cytokine concentrations in culture media of PBMCs isolated before and after a milk meal in healthy adults ${ }^{a}$

\begin{tabular}{llll}
\hline Cytokine & Hours & Pre-milk meal $(\mathrm{pg} / \mathrm{mL})$ & Post-milk meal $(\mathrm{pg} / \mathrm{mL})$ \\
\hline IL-2 & 24 & $2 \pm 0.6$ & $3 \pm 1.6$ \\
& 48 & $4 \pm 1.4$ & $5 \pm 1.9$ \\
& 72 & $1 \pm 0.3$ & $1 \pm 0.15$ \\
IL-4 & 24 & $5 \pm 1.1$ & $6 \pm 1.1$ \\
& 48 & $5 \pm 1.3$ & $6 \pm 1.4$ \\
& 72 & $3 \pm 0.7$ & $3 \pm 0.6$ \\
IL-5 & 24 & $4 \pm 0.9$ & $4 \pm 1.8$ \\
& 48 & $4 \pm 1.0$ & $4 \pm 1.1$ \\
& 72 & $1 \pm 0.2$ & $1 \pm 0.1$ \\
IL-17A & 24 & $3 \pm 0.7$ & $5 \pm 2.1$ \\
& 48 & $13 \pm 0.9$ & $13 \pm 8.8$ \\
& 72 & $1 \pm 0.1$ & $4 \pm 3.1$ \\
IFN- $\gamma$ & 24 & $3 \pm 0.8$ & $4 \pm 1.2$ \\
& 48 & $3 \pm 0.7$ & $4 \pm 1.3$ \\
& 72 & $1 \pm 0.2$ & $1 \pm 0.4$
\end{tabular}

Values are means \pm SEM, $n=12 p>0.05$ for PBMCs collected before vs. after milk consumption and treated with ConA for 24,48 and $72 \mathrm{~h}$. ConA Concanavalin A, IFN- $\gamma$ Interferon-gamma, IL interleukin 


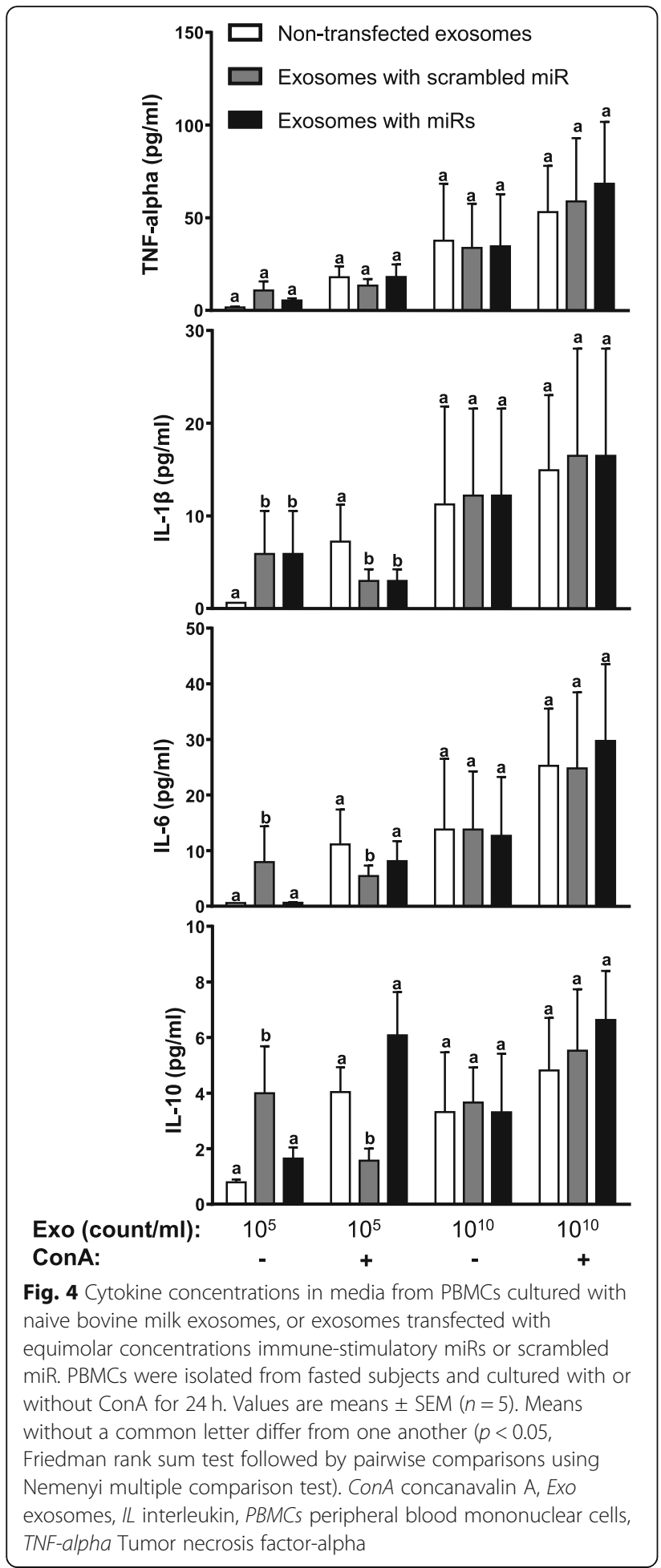

in exosome-dependent delivery of drugs will be to manipulate the homing of exosomes to sites of disease. Milk exosomes accumulate primarily in the intestinal mucosa, liver, spleen and brain in in mice and pigs, making them an attractive vehicle for delivering cargo to these locations [31].

\section{Conclusion}

Milk exosomes should be considered further as a viable option for the delivery of drugs and regulatory RNA through diet.

\section{Methods \\ Participants}

Twelve apparently healthy adults participated in this study [7 men, 5 women; age (mean \pm SD, years): $28.8 \pm$ 3.51; body mass index $\left(\right.$ mean $\left.\left.\pm \mathrm{SD}, \mathrm{kg} / \mathrm{m}^{2}\right): 23.9 \pm 2.40\right]$. For cytokine analyses in plasma, a sub-cohort of five subjects was sampled [ 2 men, 3 women; age (mean \pm SD, years): $28.4 \pm 0.58$ y; body mass index (mean $\pm \mathrm{SD}, \mathrm{kg} /$ $\mathrm{m}^{2}$ ): $\left.22.4 \pm 1.65\right]$. Exclusion criteria included pregnancy, smoking, milk allergies, and self-reported health problems. The Institutional Review Board at the University of Nebraska- Lincoln approved this protocol and all subjects signed an informed consent form. This study was retrospectively registered as a clinical trial with ISCRTN registry (ISRCTN16329971).

\section{Study design}

A within-subjects design was used, i.e., each subject served as his or her own control (pre-treatment vs. posttreatment samples). Subjects were instructed to avoid milk and other dairy products for at least $12 \mathrm{~h}$ before study begin and report to the study site after an overnight fast. A fasting blood sample was collected (time 0 $\mathrm{h}$, baseline control) after which subjects consumed $1 \mathrm{~L}$ of $1 \%$ fat bovine milk from a local grocery store in less than $10 \mathrm{~min}$. The dose of milk was based on a 26 -y-old male study subject (75 kg body weight, $1.83 \mathrm{~m}$ height) and was adjusted for the other subjects so that all subjects received the same does of milk $(0.85 \pm 0.05 \mathrm{~L}$, mean $\pm \mathrm{SD})$ per unit of total body water as described previously [49]. In a previous dose-response study $(0.25-1.0 \mathrm{~L}$ milk), we assessed the plasma-time courses of miR-29b, miR-200c and miR-1 (negative control) in healthy adults [18]. The data from the previous study informed us that $i$ ) postprandial increases of plasma miR concentrations were detectable with doses as little as $0.25 \mathrm{~L}$ milk, $i$ ) the increases were more robust if $1.0 \mathrm{~L}$ milk was consumed compared with $0.25 \mathrm{~L}$, and iii) postprandial plasma concentrations peaked at about $3-4 \mathrm{~h}$ and returned to baseline values $9 \mathrm{~h}$ after milk consumption. Based on these previous observations we rationalized that a dose of 1.0 $\mathrm{L}$ milk and postprandial blood collections at $\mathrm{t}=3,6$ and $9 \mathrm{~h}$ are appropriate choices for this study. Blood samples were collected in EDTA tubes to avoid loss of miRs by binding to heparin and inhibition of PCR by heparin residues [50, 51]. PBMCs and plasma were collected by using gradient centrifugation [52]. 


\section{Quantification of miRs in bovine milk and bovine milk- derived exosomes}

We determined presence of the immune-related miRs in bovine milk and bovine milk exosomes by using reverse transcription quantitative PCR (RT-qPCR). Bovine milk (1\% fat) was obtained from a local grocery store. Exosomes were isolated by ultracentrifugation as previously described with minor modifications [21]. RNA was isolated from bovine milk and bovine milk exosomes and reverse transcribed by using the miScript Reverse Transcription Kit following the manufacturer's instructions (Qiagen). RT-qPCR analyses for six immune-related miRs were performed using SYBR Green (Qiagen) and the universal reverse primer included in the kit plus primers specific for individual miRs (Table 4).

\section{Plasma miR analysis}

The vast majority of bovine miRs have nucleotide sequences identical to their human orthologs. Therefore, reverse transcription quantitative PCR (RT-qPCR) did not distinguish between bovine and human mature miR15b-5p, miR-21-5p, miR-34a-5p, miR-106b-5p, miR-1555p, miR-223-3p and miR-1-3p [29]. MiR-1 is not detectable in bovine milk and was used as negative control $[53,54]$. MiRs were isolated from plasma by using the NucleoSpin miRNA plasma kit (Macherey-Nagel) and assayed by reverse transcription quantitative PCR (RTqPCR) as described above. Heintz-Buschart et al. reported that spin columns for RNA purification may be contaminated with microbial RNAs and produce false positive results in miR analysis [30]. Although we could not reproduce contamination of spin columns, we opted to err on the side of caution and purified columns with $0.5 \%$ sodium hypochlorite prior to use [30]. The areas under the curves (AUCs) of plasma miRs concentration vs time curves were calculated by using the linear trapezoidal rule, and were used to assess the apparent bioavailability of miRs [55].

Table 4 Primers used for the quantification of microRNAs in human plasma ${ }^{a}$

\begin{tabular}{ll}
\hline Amplicon & Forward Primer \\
\hline miSPIKE & CTCAGGATGGCGGAGCGGTCT \\
miR-1-3p & TGGAATGTAAAGAAGTATGTAT \\
miR-15b-5p & TAGCACATCATGGTTACA \\
miR-34a-5p & TGGCAGTGTCTTAGCTGGTTG \\
miR-106b-5p & TAAAGTGCTGACAGTGCAGAT \\
miR-155-5p & TAATGCTAATCGTGATAGGGGT \\
miR-21-5p & GCTAGCTTATCAGACTGATGTGA \\
miR-223-3p & CTGTCAGTTTGTCAAATACCCCA \\
\hline
\end{tabular}

${ }^{a}$ The reverse primer is provided in the miScript SYBR Green kit (Qiagen) and its nucleotide sequence is proprietary information

\section{Cytokine analysis}

PBMCs were collected before and six hours after milk consumption and suspended in RPMI-1640 supplemented with $10 \%$ (by volume) autologous plasma, $1 \%$ penicillin/streptomycin, and $0.1 \%$ sodium pyruvate. PBMCs were grown in T25 culture flasks in a final volume of $5 \mathrm{ml}$ media at a density of $2 \times 10^{6}$ cells $/ \mathrm{ml}$. Two aliquots were prepared; one aliquot was treated with ConA at a final concentration of $15 \mu \mathrm{g} / \mathrm{ml}$ and the second aliquot was treated with solvent (vehicle control). Cells were cultured for up to three days and media supernatants were collected at $24 \mathrm{~h}, 48 \mathrm{~h}$ and $72 \mathrm{~h}$ after culture initiation. Cytokine concentrations in cell-free supernatants were determined using a customized Milliplex Map Human Cytokine/Chemokine Magnetic Bead Panel Immunoassay Kit (EMD Millipore) for IL-1 $\beta$, IL-2, IL-4, IL-5, IL-6, IL-10, IL-17A, IFN- $\gamma$ and TNF-alpha according to the manufacturer's instructions (Millipore Billerica, Inc). Samples were analyzed using a Bio-Plex Magpix reader system and Bio-Plex Manager software (Bio-Rad, Inc.).

\section{PBMC cultures with miR-loaded exosomes}

PBMCs from human fasted blood were cultured with milk exosomes or exosomes that were transfected with a mixture of synthetic immune-relevant miRs (miR-15b5p, miR-21-5p, miR-155-5p and miR-223-3p) or scrambled $\mathrm{miR}$ at a cell density of $10^{5}$ cells $/ \mathrm{ml}$ as described previously [31]. The scrambled miR was designed by randomization of the nucleotide sequences from the four immune-related miRs. Two different concentrations of exosomes $\left(1 \times 10^{5}\right.$ or $1 \times 10^{10}$ exosome particles $\left./ \mathrm{ml}\right)$ were used in PBMC cultures. Exosome-supplemented PBMC cultures were treated with ConA or solvent as described above. Cell-free culture supernatants were collected 24 and $48 \mathrm{~h}$ after culture initiation and analyzed for cytokines by using the Milliplex kit.

\section{Statistical analyses}

Two-way ANOVA and one-way ANOVA were used when testing the effects of two and one independent variables, respectively. Sidak's posthoc test was used when comparing treatments to a designated control, whereas Tukey's posthoc test was used when comparing all groups. AUCs were calculated by using GraphPad Prism 6 (GraphPad Software). Pharmacokinetics data were analyzed by using repeated-measures ANOVA Fisher's protected least significant difference test for post hoc comparisons. For cytokine analysis, Friedman rank sum test was used, followed by pairwise comparisons using Nemenyi multiple comparison test. Data are reported as means \pm SEM. Effects of treatment were considered statistically significant, if $P<0.05$. 


\section{Supplementary information}

Supplementary information accompanies this paper at https://doi.org/10. 1186/s41544-019-0041-x

Additional file 1. Box plots of TNF-alpha, IL-1 $13, \mathrm{IL}-6$, and IL-10 concentrations secreted by human PBMCs ex vivo. PBMCs were isolated before and six hours after milk consumption and incubated with or without ConA for $48 \mathrm{~h}$. Boxes represents the 5th and 95th percentiles, horizontal bars are the medians, and error bars indicate the maximum values. ${ }^{*} p<$ $0.05,{ }^{* *} p<0.01$ versus milk-free and ConA-free controls. (Friedman rank sum test followed by pairwise comparisons using Nemenyi multiple comparison test; $n=12$ ). ConA Concanavalin A, IL Interleukin, TNF-alpha Tumor necrosis factor-alpha.

Additional file 2. Box plots of TNF-alpha, IL-1 $\beta, I L-6$, and IL-10 concentrations secreted by human PBMCs ex vivo. PBMCs were isolated before and six hours after milk consumption and treated with or without ConA for $72 \mathrm{~h}$. Boxes represents the 5th and 95th percentiles, horizontal bars are the medians, and error bars indicate the maximum values. ${ }^{*} p<0.05$ versus milk-free and ConA-free controls. (Friedman rank sum test followed by pairwise comparisons using Nemenyi multiple comparison test; $n=12$ ). ConA Concanavalin A, IL Interleukin, TNF-alpha Tumor necrosis factor-alpha.

\section{Abbreviations}

ConA: Concanavalin A; Ct: Cycle threshold; IFN- : Interferon gamma; IL: Interleukin; miR: MicroRNA; PBMC: Peripheral blood mononuclear cell; RTqPCR: Reverse-transcription quantitative PCR; TNF-alpha: Tumor necrosis factor-alpha

\section{Acknowledgements}

The authors acknowledge the use of the Biomedical and Obesity Research Core and the assistance of Dr. Steven Kachman in the Nebraska Center for the Prevention of Obesity Disease through Dietary Molecules $(\mathrm{NIH}$

1P20GM104320) at the University of Nebraska- Lincoln.

\section{Authors' contributions}

J.Z. conceived the project; E.M., A.E.R.T., and J.Z. designed the research; E.M. conducted research and analyzed the data; E.M. and J.Z. wrote the manuscript; A.E.R.T. assisted with editing the paper, and J.Z. had primary responsibility for the final content. All authors read and approved the final manuscript.

\section{Funding}

Financial support provided by the NIH (grant 1P20GM104320), NIFA (grants 2015-67017-23181 and 2016-67001-25301), the Gerber Foundation, the Food for Health Initiative in the Office of the President of the University of Nebraska, the University of Nebraska Agricultural Research Division (Hatch Act), and USDA multistate group W4002 (all to J.Z.).

\section{Availability of data and materials}

All data generated during this study are included in this published article and its Additional files 1 and 2.

\section{Ethics approval and consent to participate}

The Institutional Review Board (IRB) at the University of Nebraska- Lincoln approved the protocol used in this study (IRB Approval \#: 20131013755FB), and all subjects signed an informed consent form before participation.

\section{Consent for publication}

Not applicable.

\section{Competing interests}

J.Z. serves as consultant for PureTech Health, Inc. The authors declare that they have no competing interests.

\section{Author details}

${ }^{1}$ Departments of Nutrition and Health Sciences, University of Nebraska-Lincoln, 316C Leverton Hall, Lincoln, NE 68583, USA. ${ }^{2}$ Food Science and Technology, University of Nebraska-Lincoln, 260 Food Innovation Center, Lincoln, NE 68588, USA.
Received: 3 July 2019 Accepted: 31 October 2019

Published online: 13 January 2020

\section{References}

1. Yanez-Mo M, Siljander PR, Andreu Z, Zavec AB, Borras FE, Buzas El, Buzas K, Casal E, Cappello F, Carvalho J, et al. Biological properties of extracellular vesicles and their physiological functions. J Extracell Vesicles. 2015;4:27066.

2. Huang X, Yuan T, Tschannen M, Sun Z, Jacob H, Du M, Liang M, Dittmar RL, Liu Y, Liang M, et al. Characterization of human plasma-derived exosomal RNAs by deep sequencing. BMC Genomics. 2013;14:319.

3. Raposo G, Stoorvogel W. Extracellular vesicles: exosomes, microvesicles, and friends. J Cell Biol. 2013;200(4):373-83.

4. Jing $Q$, Huang $S$, Guth S, Zarubin T, Motoyama A, Chen J, Di Padova F, Lin SC, Gram H, Han J. Involvement of microRNA in AU-rich element-mediated mRNA instability. Cell. 2005;120(5):623-34.

5. Djuranovic S, Nahvi A. Green R: miRNA-mediated gene silencing by translational repression followed by mRNA deadenylation and decay. Science. 2012;336(6078):237-40.

6. Friedman RC, Farh KK, Burge CB, Bartel DP. Most mammalian mRNAs are conserved targets of microRNAs. Genome Res. 2009;19(1):92-105.

7. University of Manchester, Faculty of Life Sciences. mirRBase 21. [database on the Internet; cited 08/28/2014]. Available from: http://www.mirbase.org/index.shtml.

8. Vojtech L, Woo S, Hughes S, Levy C, Ballweber L, Sauteraud RP, Strobl J, Westerberg K, Gottardo R, Tewari M, et al. Exosomes in human semen carry a distinctive repertoire of small non-coding RNAs with potential regulatory functions. Nucleic Acids Res. 2014:42(11):7290-304.

9. Danielson KM, Das S. Extracellular vesicles in heart disease: excitement for the future? Exosomes Microvesicles. 2014;2:1.

10. Mehta A, Baltimore D. MicroRNAs as regulatory elements in immune system logic. Nat Rev Immunol. 2016;16(5):279-94.

11. Rodriguez A, Griffiths-Jones S, Ashurst JL, Bradley A. Identification of mammalian microRNA host genes and transcription units. Genome Res. 2004;14(10A):1902-10.

12. Cheng J, Kapranov P, Drenkow J, Dike S, Brubaker S, Patel S, Long J, Stern D, Tammana $\mathrm{H}$, Helt $\mathrm{G}$, et al. Transcriptional maps of 10 human chromosomes at 5-nucleotide resolution. Science. 2005;308(5725):1149-54.

13. Consortium EP, Birney E, Stamatoyannopoulos JA, Dutta A, Guigo R, Gingeras TR, Margulies EH, Weng Z, Snyder M, Dermitzakis ET, et al. Identification and analysis of functional elements in $1 \%$ of the human genome by the ENCODE pilot project. Nature. 2007;447(7146):799-816.

14. Bernstein E, Kim SY, Carmell MA, Murchison EP, Alcorn H, Li MZ, Mills AA, Elledge SJ, Anderson KV, Hannon GJ. Dicer is essential for mouse development. Nat Genet. 2003;35(3):215-7.

15. Fukuda T, Yamagata K, Fujiyama S, Matsumoto T, Koshida I, Yoshimura K, Mihara M, Naitou M, Endoh H, Nakamura T, et al. DEAD-box RNA helicase subunits of the Drosha complex are required for processing of rRNA and a subset of microRNAs. Nat Cell Biol. 2007;9(5):604-11.

16. Chong MM, Rasmussen JP, Rudensky AY, Littman DR. The RNAselll enzyme Drosha is critical in T cells for preventing lethal inflammatory disease. J Exp Med. 2008;205(9):2005-17.

17. Zhang L, Hou D, Chen X, Li D, Zhu L, Zhang Y, Li J, Bian Z, Liang X, Cai X, et al. Exogenous plant MIR168a specifically targets mammalian LDLRAP1: evidence of cross-kingdom regulation by microRNA. Cell Res. 2012;22(1):107-26.

18. Baier SR, Nguyen C, Xie F, Wood JR, Zempleni J. MicroRNAs are absorbed in biologically meaningful amounts from nutritionally relevant doses of cow's milk and affect gene expression in peripheral blood mononuclear cells, HEK-293 kidney cell cultures, and mouse livers. J Nutr. 2014;144:1495-500.

19. Izumi H, Kosaka N, Shimizu T, Sekine K, Ochiya T, Takase M. Bovine milk contains microRNA and messenger RNA that are stable under degradative conditions. J Dairy Sci. 2012;95(9):4831-41.

20. Benmoussa A, Lee CH, Laffont B, Savard P, Laugier J, Boilard E, Gilbert C, Fliss I, Provost $P$. Commercial dairy cow milk microRNAs resist digestion under simulated gastrointestinal tract conditions. J Nutr. 2016;146(11):2206-15.

21. Wolf T, Baier SR, Zempleni J. The intestinal transport of bovine milk exosomes is mediated by endocytosis in human colon carcinoma caco-2 cells and rat small intestinal IEC-6 cells. J Nutr. 2015;145:2201-6.

22. Kusuma Jati R, Manca S, Friemel T, Sukreet S, Nguyen C, Zempleni J. Human vascular endothelial cells transport foreign exosomes from cow's milk by endocytosis. Am J Phys Cell Phys. 2016;310:C800-7.

23. Zempleni J, Aguilar-Lozano A, Sadri M, Sukreet S, Manca S, Wu D, Zhou F, Mutai E. Biological activities of extracellular vesicles and their cargos from 
bovine and human milk in humans and implications for infants. J Nutr. 2017;147(1):3-10.

24. Aguilar-Lozano A, Baier SR, Grove R, Shu J, Giraud D, Mercer KE, Cui J, Badger TM, Adamec J, Andres A, et al. Concentrations of purine metabolites are elevated in fluids from adults and infants and in livers from mice fed diets depleted of bovine milk exosomes and their RNA cargos. J Nutr. 2018; 148:1886-94.

25. Leiferman A, Shu J, Grove R, Cui J, Adamec J, Zempleni J. A diet defined by its content of bovine milk exosomes and their RNA cargos has moderate effects on gene expression, amino acid profiles and grip strength in skeletal muscle in C57BL/6 mice. J Nutr Biochem. 2018;59:123-8.

26. Munagala R, Aqil F, Jeyabalan J, Gupta RC. Bovine milk-derived exosomes for drug delivery. Cancer Lett. 2016;371(1):48-61.

27. Agrawal AK, Aqil F, Jeyabalan J, Spencer WA, Beck J, Gachuki BW, Alhakeem SS, Oben K, Munagala R, Bondada S, et al. Milk-derived exosomes for oral delivery of paclitaxel. Nanomedicine. 2017;13(5):1627-36.

28. Sun J, Aswath K, Schroeder SG, Lippolis JD, Reinhardt TA, Sonstegard TS, MicroRNA expression profiles of bovine milk exosomes in response to Staphylococcus aureus infection. BMC Genomics. 2015;16(1):806.

29. Kozomara A. Griffiths-Jones S: miRBase: annotating high confidence microRNAs using deep sequencing data. Nucleic Acids Res. 2014; 42(Database issue):D68-73.

30. Heintz-Buschart A, Yusuf D, Kaysen A, Etheridge A, Fritz JV, May P, de Beaufort C, Upadhyaya BB, Ghosal A, Galas DJ, et al. Isolation of nucleic acids from low biomass samples: detection and removal of sRNA contaminants. BMC Biol. 2018;16:52

31. Manca S, Upadhyaya B, Mutai E, Desaulniers AT, Cederberg RA, White BR, Zempleni J. Milk exosomes are bioavailable and distinct microRNA cargos have unique tissue distribution patterns. Sci Rep. 2018;8(1):11321.

32. Ross $S A$, Davis CD. The emerging role of microRNAs and nutrition in modulating health and disease. Annu Rev Nutr. 2014;34:305-36.

33. Pond SM, Tozer TN. First-pass elimination. Basic concepts and clinical consequences. Clin Pharmacokinet. 1984;9(1):1-25.

34. Bryniarski K, Ptak W, Jayakumar A, Pullmann K, Caplan MJ, Chairoungdua A, Lu J, Adams BD, Sikora E, Nazimek K, et al. Antigen-specific, antibody-coated, exosome-like nanovesicles deliver suppressor T-cell microRNA-150 to effector T cells to inhibit contact sensitivity. J Allergy Clin Immunol. 2013;132(1):170-81.

35. Fabbri M, Paone A, Calore F, Galli R, Gaudio E, Santhanam R, Lovat F, Fadda P, Mao C, Nuovo GJ, et al. MicroRNAs bind to toll-like receptors to induce prometastatic inflammatory response. Proc Natl Acad Sci U S A. 2012; 109(31):E2110-6

36. Cavalieri D, Rizzetto L, Tocci N, Rivero D, Asquini E, Si-Ammour A, Bonechi E, Ballerini C, Viola R. Plant microRNAs as novel immunomodulatory agents. Sci Rep. 2016;6:25761.

37. Potter JA, Garg M, Girard S, Abrahams VM. Viral single stranded RNA induces a trophoblast pro-inflammatory and antiviral response in a TLR8-dependent and -independent manner. Biol Reprod. 2015;92(1):17.

38. Tatematsu M, Nishikawa F, Seya T, Matsumoto M. Toll-like receptor 3 recognizes incomplete stem structures in single-stranded viral RNA. Nat Commun. 2013;4:1833.

39. Zhang SY, Herman M, Ciancanelli MJ. Perez de Diego R, Sancho-Shimizu V, Abel L, Casanova JL: TLR3 immunity to infection in mice and humans. Curr Opin Immunol. 2013;25(1):19-33.

40. Isorce N, Testoni B, Locatelli M, Fresquet J, Rivoire M, Luangsay S, Zoulim F, Durantel $D$. Antiviral activity of various interferons and pro-inflammatory cytokines in non-transformed cultured hepatocytes infected with hepatitis B virus. Antivir Res. 2016;130:36-45.

41. Vandenbon A, Teraguchi S, Akira S, Takeda K, Standley DM. Systems biology approaches to toll-like receptor signaling. Wiley Interdiscip Rev Syst Biol Med. 2012;4(5):497-507.

42. Wiklander OP, Nordin JZ, O'Loughlin A, Gustafsson Y, Corso G, Mager I, Vader $P$, Lee $Y$, Sork $H$, Seow $Y$, et al. Extracellular vesicle in vivo biodistribution is determined by cell source, route of administration and targeting. J Extracell Vesicles. 2015;4:26316

43. Imai T, Takahashi Y, Nishikawa M, Kato K, Morishita M, Yamashita T, Matsumoto A, Charoenviriyakul C, Takakura Y. Macrophage-dependent clearance of systemically administered B16BL6-derived exosomes from the blood circulation in mice. J Extracell Vesicles. 2015;4:26238.

44. Izumi H, Tsuda M, Sato Y, Kosaka N, Ochiya T, Iwamoto H, Namba K, Takeda Y. Bovine milk exosomes contain microRNA and mRNA and are taken up by human macrophages. J Dairy Sci. 2015;98(5):2920-33.
45. Zempleni J. Biokinetic analysis of vitamin absorption and disposition in humans. Methods Enzymol. 1997;281:405-25.

46. Rodriguez-Melendez R, Camporeale G, Griffin JB, Zempleni J. Interleukin-2 receptor $\mathrm{g}$-dependent endocytosis depends on biotin in Jurkat cells. Am J Phys Cell Phys. 2003;284:C415-21.

47. Kamerkar S, LeBleu VS, Sugimoto H, Yang S, Ruivo CF, Melo SA, Lee JJ, Kalluri R. Exosomes facilitate therapeutic targeting of oncogenic KRAS in pancreatic cancer. Nature. 2017:546(7659):498-503.

48. Couper KN, Blount DG, Riley EM. IL-10: the master regulator of immunity to infection. J Immunol. 2008;180(9):5771-7.

49. Watson PE, Watson ID, Batt RD. Total body water volumes for adult males and females estimated from simple anthropometric measurements. Am J Clin Nutr. 1980;33(1):27-39.

50. Balaj L, Atai NA, Chen W, Mu D, Tannous BA, Breakefield XO, Skog J, Maguire CA. Heparin affinity purification of extracellular vesicles. Sci Rep. 2015;5:10266.

51. Wang L, Sadri M, Giraud D, Zempleni J. RNase H2-dependent polymerase chain reaction and elimination of confounders in sample collection, storage, and analysis strengthen evidence that microRNAs in bovine milk are bioavailable in humans. J Nutr. 2018;148(1):153-9.

52. Zempleni J, Mock DM. Mitogen-induced proliferation increases biotin uptake into human peripheral blood mononuclear cells. Am J Phys Cell Phys. 1999;276(5):C1079-84.

53. Chen X, Gao C, Li H, Huang L, Sun Q, Dong Y, Tian C, Gao S, Dong H, Guan $D$, et al. Identification and characterization of microRNAs in raw milk during different periods of lactation, commercial fluid, and powdered milk products. Cell Res. 2010;20(10):1128-37.

54. Munch EM, Harris RA, Mohammad M, Benham AL, Pejerrey SM, Showalter L, Hu M, Shope CD, Maningat PD, Gunaratne PH, et al. Transcriptome profiling of microRNA by next-gen deep sequencing reveals known and novel miRNA species in the lipid fraction of human breast milk. PLoS One. 2013; 8(2):e50564

55. Zempleni J, Galloway JR, McCormick DB. Pharmacokinetics and utilization of orally and intravenously administered riboflavin in healthy humans. Am J Clin Nutr. 1996;63:54-66.

\section{Publisher's Note}

Springer Nature remains neutral with regard to jurisdictional claims in published maps and institutional affiliations.

\section{Ready to submit your research? Choose BMC and benefit from:}

- fast, convenient online submission

- thorough peer review by experienced researchers in your field

- rapid publication on acceptance

- support for research data, including large and complex data types

- gold Open Access which fosters wider collaboration and increased citations

- maximum visibility for your research: over $100 \mathrm{M}$ website views per year

At BMC, research is always in progress.

Learn more biomedcentral.com/submissions 